\title{
Atrial Natriuretic Factor Inhibits Vasopressin-stimulated Osmotic Water Permeability in Rat Inner Medullary Collecting Duct
}

\author{
Hiroshi Nonoguchi, Jeff M. Sands, and Mark A. Knepper \\ Laboratory of Kidney and Electrolyte Metabolism, National Heart, Lung and Blood Institute, \\ National Institutes of Health, Bethesda, Maryland 20892
}

\begin{abstract}
The inner medullary collecting duct (IMCD) has been proposed to be a site of atrial natriuretic factor (ANF) action. We carried out experiments in isolated perfused terminal IMCDs to determine whether ANF (rat ANF 1-28) affects either osmotic water permeability $\left(\boldsymbol{P}_{\boldsymbol{f}}\right)$ or urea permeability. In the presence of a submaximally stimulating concentration of vasopres$\sin \left(10^{-11} \mathrm{M}\right)$, ANF (100 $\left.\mathrm{nM}\right)$ significantly reduced $P_{f}$ by an average of $46 \%$. Lower concentrations of ANF also significantly inhibited vasopressin-stimulated $\boldsymbol{P}_{\mathrm{f}}$ by the following percentages: 0.01 nM ANF, 18\%; 0.1 nM, 46\%; 1 nM, 48\%. Addition of exogenous cyclic GMP (0.1 mM) mimicked the effect of ANF, decreasing $P_{f}$ by an average of $48 \%$. ANF also inhibited cyclic AMP-stimulated $P_{f}$ by an average of $31 \%$. ANF did not affect urea permeability, nor did it alter vasopressin-stimulated cyclic AMP accumulation. We conclude that ANF at physiological concentrations causes a large inhibition of vasopressin-stimulated $P_{f}$ in the rat terminal IMCD, and that cyclic GMP is the second messenger mediating the effect. ANF appears to act at a site distal to cyclic AMP generation in the chain of events linking vasopressin receptor binding to an increase in osmotic water permeability.
\end{abstract}

\section{Introduction}

It is now generally accepted that atrial natriuretic factor (ANF) $)^{1}$ is a circulating hormone involved in the regulation of extracellular fluid volume and blood pressure. Several endorgan responses have been identified. As detailed in recent reviews (1-3), ANF relaxes vascular smooth muscle, inhibits renin secretion, inhibits aldosterone production by the adrenal cortex, and increases renal $\mathrm{NaCl}$ and water excretion. Several

Portions of this manuscript were presented at the 19th and 20th Annual Meetings of the American Society of Nephrology, Washington, DC, December 1986 and December 1987, and have been published in abstract form (1987. Kidney Int. 31:450; and 1988. Kidney Int. 33:278).

Dr. Nonoguchi's current address is Second Department of Internal Medicine, Tokyo Medical and Dental University, 5-45, Yushima 1Chome, Bunkyo-Ku, Tokyo 113, Japan.

Dr. Sands' current address is Renal Division, Emory University School of Medicine, 1364 Clifton Road, NE, Atlanta, GA 30322.

Address reprint requests to Dr. Knepper, NIH, Bldg. 10, Room 6N-307, Bethesda, MD 20892.

Received for publication 4 December 1987 and in revised form 10 May 1988.

1. Abbreviations used in this paper: ANF, atrial natriuretic factor; AVP, arginine vasopressin; IBMX, 3-isobutyl-1-methylxanthine; IMCD, inner medullary collecting duct; $P_{\mathrm{f}}$, osmotic water permeability.

The Journal of Clinical Investigation, Inc.

Volume 82, October 1988, 1383-1390 renal actions of ANF have been identified which can contribute to the increase in $\mathrm{NaCl}$ and water excretion. These actions include increases in glomerular filtration rate and in filtration fraction, inhibition of tubular-glomerular feedback, increases in inner medullary blood flow, and direct effects on renal tubular transport (1-3).

The evidence for direct tubular actions of ANF has been steadily increasing, with the collecting duct appearing to be a major site of action. Briggs et al. (4) showed that low concentrations of atrial extracts induced natriuresis and diuresis in the absence of a measurable increase in GFR, a result which has been confirmed using low-dose infusion of synthetic ANF (5-8). Briggs et al. (4) found no evidence for an effect of ANF on $\mathrm{NaCl}$ transport in either the proximal tubule or the loop of Henle. Thus they concluded that there must be an effect of ANF beyond the distal convoluted tubule, i.e., in the collecting duct system. Similar studies by Sonnenberg et al. (9) also supported the view that ANF inhibits $\mathrm{NaCl}$ reabsorption in the medullary collecting duct. Other evidence points to the inner medullary collecting duct as a likely site of ANF action. Nonoguchi et al. (10) have demonstrated that ANF causes a large increase in cyclic GMP production in the terminal part of the inner medullary collecting duct (terminal IMCD). Binding studies using autoradiography have shown high-affinity binding sites for ANF in the inner medulla (11-13) thought to be associated with the vasa recta and/or inner medullary collecting ducts. Furthermore, there is evidence from in vivo studies in rats that $\mathrm{ANF}$ inhibits $\mathrm{NaCl}$ and water absorption in the inner medullary collecting duct $(14,15)$. Finally, Zeidel et al. (16) have shown that ouabain-inhibitable oxygen consumption, an indirect measure of $\mathrm{NaCl}$ transport, is decreased by ANF in suspensions of rabbit collecting duct cells isolated from the inner medulla. Thus, there is considerable evidence pointing to the IMCD as a likely site of ANF action.

In the present study, to examine more closely the possibility that ANF can directly affect transport in the IMCD, we have employed the isolated perfused tubule technique. Specifically, we have tested the effects of ANF on vasopressin-stimulated osmotic water permeability and urea permeability of isolated perfused inner medullary collecting ducts.

Previous studies have shown that vasopressin stimulates both osmotic water permeability and urea permeability in the rat terminal IMCD (17-19). The studies presented here, in isolated perfused tubules from the terminal part of the IMCD, show that physiological concentrations of ANF significantly inhibit vasopressin-stimulated osmotic water permeability without affecting urea permeability. The effect on osmotic water permeability is large and, if present in vivo, is predictive of a major effect on renal water excretion. The results also show that exogenous cyclic GMP mimics the inhibitory action of ANF suggesting that cyclic GMP is the second messenger, and that the ANF effect is not dependent on a change in cyclic AMP metabolism. 


\section{Methods}

Tissue preparation. Terminal inner medullary collecting duct segments were dissected from the kidneys of pathogen-free male SpragueDawley rats weighing 65-140 g (Small Animal Breeding Facility, National Institutes of Health, Bethesda, MD) using methods described previously (20). 20 min before death by decapitation, the animals were injected with furosemide $(5 \mathrm{mg} / 100 \mathrm{~g}$ of body wt i.p.) to create a brisk diuresis and presumably wash out the medullary osmolality gradient (20).

The kidneys were removed and placed in chilled isotonic dissection medium (described below). Coronal slices were cut from the kidneys and transferred to a dissection dish containing chilled $\left(17^{\circ} \mathrm{C}\right)$ dissection solution for isolation of terminal IMCDs. The dissection medium contained (in millimolar): $\mathrm{NaCl}, 118 ; \mathrm{NaHCO}_{3}, 25 ; \mathrm{CaCl}_{2}, 2$; $\mathrm{K}_{2} \mathrm{HPO}_{4}, 2.5 ; \mathrm{MgSO}_{4}, 1.2 ;$ glucose, 5.5 ; creatinine, 4 ; raffinose, 5 ; and urea, 5 . It was gassed continuously with $95 \%$ air and $5 \% \mathrm{CO}_{2}$ before and during the dissection.

Terminal IMCDs were dissected from carefully localized positions along the inner medullary axis as previously described (20). Terminal IMCDs are defined as those collecting ducts whose proximal-most end originated in the two-thirds of the inner medulla closest to the papillary tip (17). The tubules were mounted on concentric pipettes as described previously (21) and were studied at $37^{\circ} \mathrm{C}$.

Osmotic water permeability. Osmotic water permeability was determined by measuring the water flux resulting from an imposed osmotic gradient. For these experiments, the perfusion and bath solutions were identical to the dissection medium (described above) except that an additional $106 \mathrm{mM} \mathrm{NaCl}$ was added to the bath. This created a $200 \mathrm{mosmol} / \mathrm{kg} \mathrm{H}_{2} \mathrm{O}$ bath-to-lumen osmolality gradient. The osmolalities of the perfusate and bath were measured by vapor pressure osmometry (Wescor, Inc., Logan, UT) before the start of each experiment allowing the calculation of the actual osmolality gradient.

Creatinine was used as the volume marker for the measurement of osmotic water permeability $\left(P_{f}\right)$. We have previously shown that the creatinine permeability in terminal IMCDs is low and that the error in measuring $P_{\mathrm{f}}$ due to creatinine fluxes, under the conditions of our study, is $<4 \%(17,20)$. To calculate osmotic water permeability, the perfusion rate $\left(V_{0}\right)$ was first calculated from the collection rate $\left(V_{L}\right)$ using: $V_{0}=V_{\mathrm{L}} \cdot\left(X_{\mathrm{L}} / X_{0}\right)$, where $X_{\mathrm{L}}$ and $X_{0}$ are, respectively, the collected and perfused concentrations of creatinine. Then the $P_{\mathrm{f}}$ was calculated using the equation of Al-Zahid et al. (22):

$P_{\mathrm{f}}=-\frac{V_{0} C_{0}}{A V_{\mathrm{w}}}\left[\frac{C_{0}-C_{\mathrm{L}}}{C_{0} C_{\mathrm{b}} C_{\mathrm{L}}}+\frac{1}{\left(C_{\mathrm{b}}\right)^{2}} \ln \frac{\left(C_{\mathrm{L}}-C_{\mathrm{b}}\right) C_{0}}{\left(C_{0}-C_{\mathrm{b}}\right) C_{\mathrm{L}}}\right]$

where $C_{0}$ and $C_{\mathrm{b}}$ are the osmolalities of the perfusate and bath, respectively, $A$ is the luminal surface area, $V_{w}$ is the partial molar volume of water, and $C_{\mathrm{L}}$ is the calculated collected fluid osmolality, defined as: $C_{\mathrm{L}}$ $=C_{0} \cdot\left(V_{0} / V_{\mathrm{L}}\right)$. The luminal surface area, $A$, was calculated as $A=\pi D L$ from the measured tubule length $(L)$ and diameter $(D)$ determined from Polaroid photographs of the perfused tubule. We have previously shown (17) that $\mathrm{NaCl}$ fluxes in the terminal IMCD, under the conditions of this study, are low enough to allow use of the equation of Al-Zahid et al. (22).

The creatinine concentrations in perfusate, bath, and collected fluid were measured using a continuous flow ultramicrocolorimeter as previously described (23). The reagents were purchased as a kit (Kit 555-A, Sigma Chemical Co., St. Louis, MO). The method is linear up to 150 pmol creatinine and is capable of resolving differences of $3 \%$ between samples in the size range 50-150 pmol.

In a previous study (17), we performed time-control experiments which demonstrated that the basal osmotic water permeability remained at a steady level between 40 and $150 \mathrm{~min}$. All reported measurements of $P_{\mathrm{f}}$ in the absence of hormone, after addition of atrial natriuretic factor (rat ANF 1-28, Peninsula Laboratories, Inc., Belmont, CA), after addition of arginine vasopressin (Sigma Chemical
Co.), or after addition of 8-bromo-cyclic AMP (sodium salt, Sigma Chemical Co.) were completed during this stable period between $\mathbf{4 0}$ and $150 \mathrm{~min}$ after warming the tubule to $37^{\circ} \mathrm{C}$.

Urea permeability. To measure urea permeability, the net flux of urea was measured in response to an imposed $5 \mathrm{mM}$ bath-to-lumen urea concentration gradient. For these experiments, the perfusion and bath solutions were identical to the dissection medium (described above) except that the bath contained $5 \mathrm{mM}$ urea (without raffinose) and the perfusate contained $5 \mathrm{mM}$ raffinose (without urea). The urea transport rate $\left(J_{\mathrm{u}}\right)$ was calculated as: $J_{\mathrm{u}}=\left(c_{0} \cdot V_{0}-c_{\mathrm{L}} \cdot V_{\mathrm{L}}\right) / L$, where $c_{0}$ is the urea concentration in the perfusate, $c_{\mathrm{L}}$ is the urea concentration in the collected fluid, $V_{0}$ is the perfusion rate, and $V_{\mathrm{L}}$ is the collection rate, and $L$ is the tubule length. The perfusate urea concentration $\left(c_{0}\right)$ was zero for all experiments, thus obviating any need to measure $V_{0}$. The urea permeability $\left(P_{\mathrm{u}}\right)$ was calculated from the urea transport rate $\left(J_{\mathrm{u}}\right)$ using the equation: $P_{\mathrm{u}}=J_{\mathrm{u}} /(\pi \cdot D \cdot \Delta c)$, where $\Delta c$ is the mean urea concentration difference along the tubule and $D$ is the tubule inner diameter measured from Polaroid photographs of the perfused tubule.

The urea concentrations in perfusate, bath, and collected fluid were measured enzymatically using a continuous flow ultramicrofluorometer (20). The reagents were purchased as a kit (Kit 65-A, Sigma Chemical Co.). The method is linear from 0 to $60 \mathrm{pmol}$ urea and is capable of resolving differences of $4 \%$ or greater in urea content between samples in the size range used in these experiments (12-36 pmol).

In a previous study (17), we performed time-control experiments which demonstrated that the basal urea permeability remained at a steady level between 40 and $120 \mathrm{~min}$. All reported measurements of $P_{\mathrm{u}}$ in the absence of hormone, after addition of ANF or after addition of arginine vasopressin were completed during this stable period between 40 and $120 \mathrm{~min}$ after warming the tubule to $37^{\circ} \mathrm{C}$.

Cyclic AMP accumulation studies. To test whether ANF inhibits the vasopressin-stimulated rate of cyclic AMP production, terminal IMCDs were microdissected and cyclic AMP was measured by radioimmunoassay as previously described (10). Two solutions were used for the cyclic AMP studies. Solution A was bicarbonate buffered and consisted of (in millimolar): $\mathrm{NaCl}, 117 ; \mathrm{KCl}, 5 ; \mathrm{NaH}_{2} \mathrm{PO}_{4}, 1 ; \mathrm{MgSO}_{4}$, $1.2 ; \mathrm{CaCl}_{2}, 2$; glucose, $5.5 ; \mathrm{L}$-alanine, 6 ; and $\mathrm{NaHCO}_{3}, 25$. Solution B was Hepes buffered and differed from solution $A$ only in that the $\mathrm{NaHCO}_{3}$ was replaced by Hepes $(10 \mathrm{mM})$ and the $\mathrm{NaCl}$ was increased to $135 \mathrm{mM}$. (The $\mathrm{pH}$ was titrated to 7.4 by the addition of $\mathrm{NaOH}$.)

Briefly, the left kidney was perfused with $10 \mathrm{ml}$ of ice-cold solution $A$ and then perfused with $10 \mathrm{ml}$ of solution A containing $0.1 \%$ collagenase. Coronal slices containing the inner medulla were torn into four pieces and incubated in solution A containing $0.1 \%$ collagenase for 30 min at $37^{\circ} \mathrm{C}$. The solution was gassed with $95 \%$ air and $5 \% \mathrm{CO}_{2}$. After incubation, the slices were washed with ice-cold solution B. Terminal IMCDs were microdissected at $17^{\circ} \mathrm{C}$ in solution B containing $0.05 \%$ BSA. After measuring tubule length using an ocular micrometer, tubules were transfered with $2 \mu \mathrm{l}$ of dissection solution into $18 \mu \mathrm{l}$ of solution B either with or without $0.56 \mathrm{mM} 3$-isobutyl-1-methylxanthine (IBMX). In the experiments with IBMX, the mean tubule length for each sample was $4.04 \mathrm{~mm}$. In the experiments without IBMX, the mean tubule length was $8.95 \mathrm{~mm}$.

During the subsequent incubations, ANF, if present, was used at a final concentration of $100 \mathrm{nM}$; and vasopressin, if present, was used at a final concentration of $10^{-11} \mathrm{M}$. Tubules were preincubated for 10 min at $37^{\circ} \mathrm{C}$ at 50 oscillations/min in a shaking water bath. Next, $20 \mu l$ of solution B containing ANF or vehicle, with or without $0.5 \mathrm{mM}$ IBMX, was added. After incubation for $3 \mathrm{~min}, 20 \mu \mathrm{l}$ of solution B containing vasopressin, with or without $0.5 \mathrm{mM}$ IBMX, was added. All of the solutions were prewarmed at $37^{\circ} \mathrm{C}$. In the experiments with IBMX, incubation after the addition of vasopressin was continued for $5 \mathrm{~min}$. In the experiments without IBMX, incubation after the addition of vasopressin was continued for $10 \mathrm{~min}$. The reaction was stopped by the addition of $70 \mu \mathrm{l}$ of $10 \%$ trichloroacetic acid and the sample tubes were vortexed immediately. Each tube was centrifuged and $115 \mu \mathrm{l}$ of supernatant was stored in a glass test tube at $-20^{\circ} \mathrm{C}$ until 
assayed. Blank samples for standards were prepared in a similar fashion.

In order to perform the cyclic AMP assay, the samples were thawed and the trichloroacetic acid was extracted by water-saturated ether. After evaporation of the ether, the remaining aqueous phase was dried in a speed vacuum concentrator. Next, $100 \mu \mathrm{l}$ of $50 \mathrm{mM}$ sodium acetate buffer ( $\mathrm{pH} 6.2)$ was added to each sample. $(100 \mu \mathrm{l}$ of $50 \mathrm{mM}$ sodium acetate buffer with the appropriate cyclic AMP standard was added to each blank sample.) Previously, we have shown that the recovery of added cyclic AMP using this method was $99.0 \pm 5.2 \%$ $(n=11)(10)$. Cyclic AMP content was measured by radioimmunoassay (Kit NEK-033, New England Nuclear, Boston, MA). Using this RIA kit, $50 \%$ of the tracer was displaced at $84.9 \pm 1.6 \mathrm{fmol}$ of cyclic $\operatorname{AMP}(n=4)$.

Statistics. Two to four measurements of each variable were averaged to obtain a single value for each experimental condition in each tubule. These average values were used in the statistical analysis of the results. Testing of statistical significance employed a Student's t-test, either paired or unpaired, as appropriate, with $P<0.05$ indicating statistical significance.

\section{Results}

ANF effect on vasopressin-stimulated osmotic water permeability. In these experiments (Fig. 1), vasopressin $\left(10^{-11} \mathrm{M}\right)$ was present in the bath throughout, and either ANF (100 nM) or vehicle was added to the bath after control measurements were made. ANF significantly inhibited $P_{\mathrm{f}}$ by $46.5 \pm 11.0 \%$ (Fig. 1, left panel). When vehicle alone was added, there was no significant change in $P_{\mathrm{f}}$ (Fig. 1, right panel). An effect of ANF was seen within 20 min after adding ANF to the bath.

$A N F$ dose response. Plasma ANF concentrations in rats have been reported to range from $0.01 \mathrm{nM}$ under basal conditions to $0.1 \mathrm{nM}$ under conditions which stimulate ANF release (24). We tested whether concentrations of ANF in the physiologic range would inhibit vasopressin-stimulated $P_{\mathrm{f}}$. The peritubular bath contained $10^{-11} \mathrm{M}$ vasopressin throughout and ANF was added after control measurements. As described in detail in Table I (series 1-4) and summarized in Fig. 2, $0.1 \mathrm{nM}$ ANF, $1 \mathrm{nM}$ ANF, and $100 \mathrm{nM}$ ANF all caused large inhibitions of vasopressin-stimulated $P_{\mathrm{f}}$, decreasing $P_{\mathrm{f}}$ by $45.5 \pm 6.2 \%, 48.0 \pm 7.5 \%$, and $46.5 \pm 11.0 \%$, respectively. 0.01 nM ANF caused a smaller, but significant, inhibition of vasopressin-stimulated $P_{\mathrm{f}}$, decreasing $P_{\mathrm{f}}$ by $18.2 \pm 8.7 \%$. Without ANF addition there was no significant change in $P_{\mathrm{f}}$. Thus, the dose-response data are compatible with an inhibition by ANF of vasopressin-stimulated $P_{\mathrm{f}}$ at physiological ANF concentrations.

Response to cyclic GMP and 8-bromo-cyclic GMP. Cyclic GMP is the second messenger responsible for many of the actions of ANF in various tissues (25-29). In the present studies, $0.1 \mathrm{mM}$ cyclic GMP added to the peritubular bath inhibited vasopressin-stimulated osmotic water permeability by $48.0 \pm 5.4 \%$ (Fig. 3). This result is compatible with the conclusion that cyclic GMP is the second messenger that mediates the inhibition of $P_{\mathrm{f}}$ by ANF.

We also tested the effect of a cyclic GMP analogue 8bromo-cyclic GMP on vasopressin-stimulated $P_{\mathrm{f}}$. In contrast to cyclic GMP, 8-bromo-cyclic GMP $(0.1 \mathrm{mM})$ addition did not affect vasopressin-stimulated $P_{\mathrm{f}}$ (Fig. 4). Thus, 8-bromocyclic GMP had a much different effect than did the natural form of cyclic GMP.

Vasopressin dose dependence. ANF did not affect $P_{\mathrm{f}}$ in the absence of vasopressin (left bars, Fig. 5) or in the presence of a very high concentration of vasopressin $\left(10^{-8} \mathrm{M}\right.$, Fig. 5, right bars). These results contrast with the previous observation that ANF inhibited osmotic water permeability in the presence of a submaximally stimulating concentration of vasopressin $\left(10^{-11}\right.$ $\mathrm{M})$, repeated as the middle bars in Fig. 5 for comparison. A detailed summary of these experiments is presented in Table I (series 4-6).

Urea permeability. ANF (100 nM) had no significant effect on either the basal urea permeability (Fig. 6, left bars) or the urea permeability in the presence of $10^{-11} \mathrm{M}$ vasopressin (Fig. 6 , right bars). A detailed summary of these experiments is presented in Table II.

Cyclic AMP accumulation. To test whether ANF inhibits the production of cyclic AMP in the presence of $10^{-11} \mathrm{M}$ vasopressin, cyclic AMP accumulation was measured in microdissected unperfused terminal IMCDs. ANF (100 nM) had no effect on the vasopressin-stimulated rate of cyclic AMP formation, either in the presence of IBMX $(0.5 \mathrm{mM}$, Fig. 7, left panel) or in the absence of IBMX (Fig. 7, right panel).

$A N F$ effect on cyclic AMP-stimulated osmotic water permeability. In further experiments, we tested the ability of ANF to inhibit cyclic AMP-stimulated $P_{\mathrm{f}}$. The cyclic AMP analogue, 8-bromo-cyclic AMP $\left(10^{-3} \mathrm{M}\right)$, was added to the peritubular bath throughout each experiment. ANF (10 $\mathrm{nM})$ significantly inhibited 8-bromo-cyclic AMP-stimulated osmotic water per-
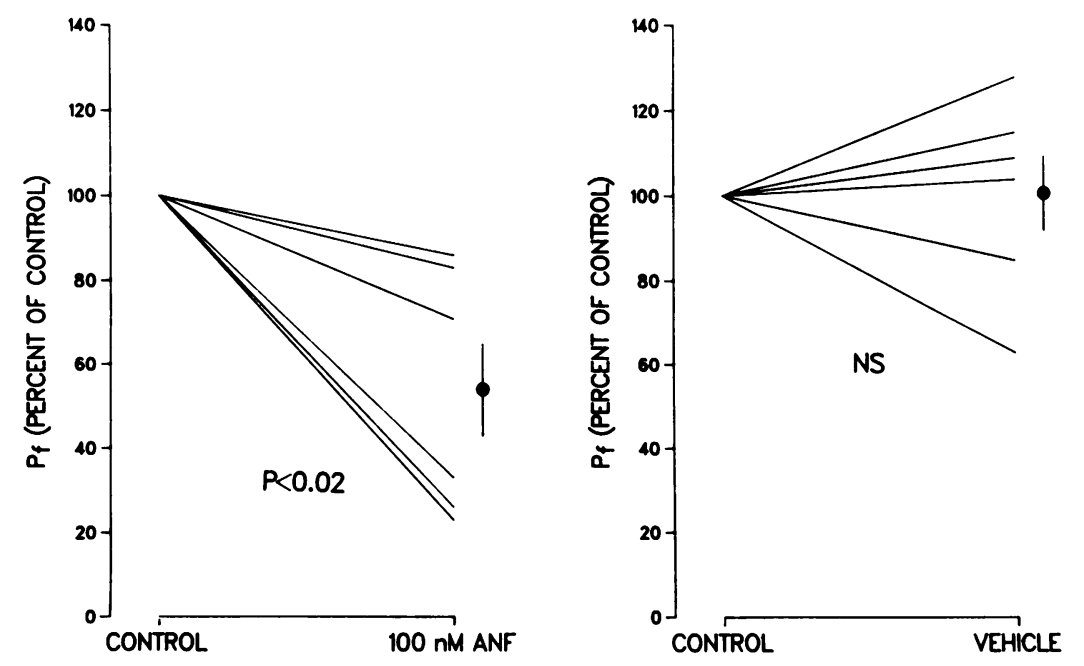

Figure 1. The effect of $100 \mathrm{nM}$ ANF (left) and vehicle (right) on vasopressin-stimulated osmotic water permeability $\left(P_{\mathrm{f}}\right)$. Vasopressin was present throughout each experiment at a concentration of $10^{-11} \mathrm{M}$. Each line represents the result in one tubule. Mean $\pm \mathrm{SE}$ is shown at right side of each panel. 
Table I. Osmotic Water Permeability

\begin{tabular}{|c|c|c|c|c|c|c|}
\hline Length & Diameter & [AVP] & [ANF] & Coll. rate & $\begin{array}{l}\text { [Creatinine] } \\
\text { coll./perf. }\end{array}$ & $P_{\mathrm{f}}$ \\
\hline$\mu m$ & $\mu m$ & $M$ & $M$ & $\mathrm{nl} / \mathrm{min}$ & & $\mu m / s$ \\
\hline \multicolumn{7}{|c|}{ Series $1(n=6)$ : } \\
\hline \multirow[t]{2}{*}{$690 \pm 90$} & $32 \pm 2$ & $10^{-11}$ & 0 & $9.24 \pm 1.70$ & $1.24 \pm 0.05$ & $193.8 \pm 64.7$ \\
\hline & & $10^{-11}$ & 0 & $8.41 \pm 1.80$ & $1.26 \pm 0.06$ & $191.6 \pm 68.2$ \\
\hline \multicolumn{7}{|c|}{ Series $2(n=6)$ : } \\
\hline \multirow[t]{3}{*}{$590 \pm 60$} & $30 \pm 1$ & $10^{-11}$ & 0 & $6.67 \pm 0.40$ & $1.33 \pm 0.07$ & $285.5 \pm 82.5$ \\
\hline & & $10^{-11}$ & $10^{-11}$ & $6.30 \pm 0.59$ & $1.27 \pm 0.07$ & $196.4^{*} \pm 50.9$ \\
\hline & & $10^{-11}$ & $10^{-10}$ & $6.41 \pm 0.55$ & $1.22 \pm 0.06$ & $151.7^{*} \pm 50.5$ \\
\hline \multicolumn{7}{|c|}{ Series $3(n=5)$ : } \\
\hline \multirow[t]{2}{*}{$500 \pm 60$} & $28 \pm 1$ & $10^{-11}$ & 0 & $4.91 \pm 0.48$ & $1.32 \pm 0.08$ & $220.0 \pm 58.3$ \\
\hline & & $10^{-11}$ & $10^{-9}$ & $4.79 \pm 0.92$ & $1.18 \pm 0.04$ & $96.2 * \pm 18.5$ \\
\hline \multicolumn{7}{|c|}{ Series $4(n=6)$ : } \\
\hline \multirow[t]{2}{*}{$540 \pm 50$} & $30 \pm 2$ & $10^{-11}$ & 0 & $6.39 \pm 0.39$ & $1.23 \pm 0.04$ & $161.4 \pm 23.1$ \\
\hline & & $10^{-11}$ & $10^{-7}$ & $5.99 \pm 0.34$ & $1.14 \pm 0.03$ & $89.3^{*} \pm 24.3$ \\
\hline \multicolumn{7}{|c|}{ Series $5(n=5)$ : } \\
\hline \multirow[t]{2}{*}{$490 \pm 40$} & $28 \pm 1$ & 0 & 0 & $5.29 \pm 0.77$ & $1.07 \pm 0.02$ & $41.6 \pm 15.4$ \\
\hline & & 0 & $10^{-7}$ & $5.29 \pm 0.75$ & $1.07 \pm 0.02$ & $41.7 \pm 10.3$ \\
\hline \multicolumn{7}{|c|}{ Series $6(n=5)$ : } \\
\hline \multirow[t]{2}{*}{$420 \pm 20$} & $33 \pm 2$ & $10^{-8}$ & 0 & $5.28 \pm 0.65$ & $1.39 \pm 0.03$ & $316.9 \pm 54.0$ \\
\hline & & $10^{-8}$ & $10^{-7}$ & $4.42 \pm 0.25$ & $1.40 \pm 0.04$ & $309.3 \pm 61.5$ \\
\hline
\end{tabular}

* $P_{\mathrm{f}}$ significantly different from value in the absence of ANF, by paired $t$ test. All data are presented as mean $\pm S E$. Diameter is tubule inner diameter. $P_{f}$, osmotic water permeability coefficient; Coll., collection; Perf., perfusate; [AVP], vasopressin concentration; [ANF], ANF concentration; $n$, number of tubules.

meability by $30.9 \pm 4.8 \%(n=5)$, decreasing $P_{\mathrm{f}}$ from $455.0 \pm 93.0$ to $297.2 \pm 41.8(n=5, P<0.04)$. In time control experiments in which vehicle alone was added, no significant change occurred in $P_{\mathrm{f}}$ (from 393.9 \pm 84.0 to $399.9 \pm 82.3, n=5$ ).

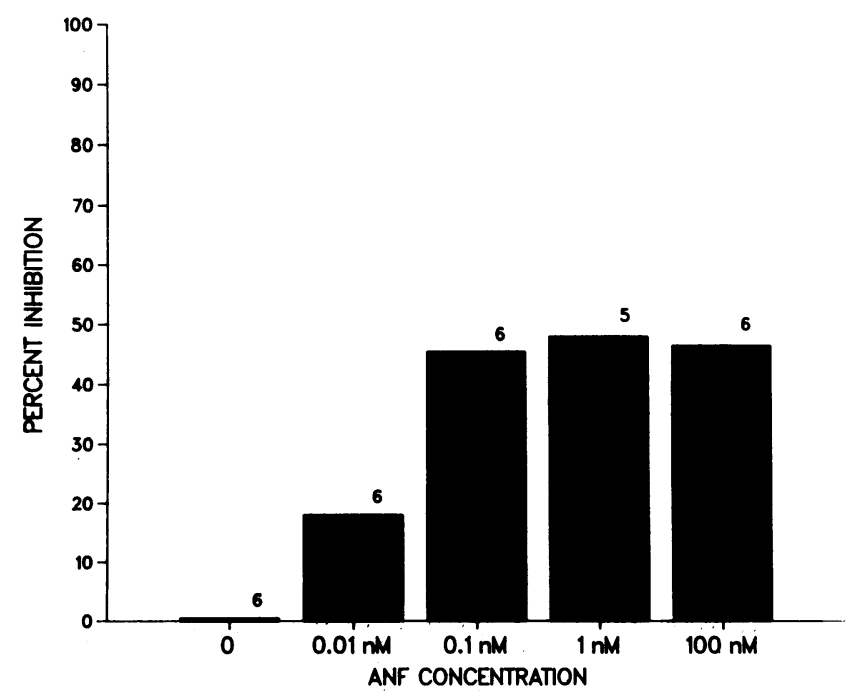

Figure 2. Relation between ANF dose and $P_{\mathrm{f}}$ inhibition. Vasopressin was present throughout each experiment at a concentration of $10^{-11}$ $M$. Bars show mean at each dose. Responses to all non-zero concentrations of ANF were statistically significant $(P<0.05)$. The $100 \mathrm{nM}$ ANF data is the same as that in Fig. 1. In two additional tubules (not shown), the $P_{\mathrm{f}}$ increased by $32.2 \%$ and $65.5 \%$, respectively, when 0.1 nM ANF was washed out of the bath.

\section{Discussion}

Since the observation by DeBold et al. (30) that atrial extracts induce natriuresis and diuresis, considerable progress has been made in understanding the physiology of ANF action (1-3). Despite this progress, the precise physiological mechanism of ANF action in the kidney remains to be fully elucidated. It was our goal in this study to determine whether ANF directly affects osmotic water permeability or urea permeability in the rat terminal IMCD.

ANF inhibits vasopressin-stimulated osmotic water permeability. The chief new finding in this study is that ANF inhibits vasopressin-stimulated osmotic water permeability in the rat terminal IMCD. ANF, at concentrations of $0.1 \mathrm{nM}$ or higher, caused nearly a $50 \%$ decrease in osmotic water permeability. At $0.01 \mathrm{nM}$, ANF caused a smaller decrease in osmotic water permeability (18\%). Plasma levels of ANF in rats have been reported in a number of studies, and while not all investigators agree, most of the studies have reported a basal plasma ANF concentration in rats of $\sim 0.01 \mathrm{nM}$. For example, Ballermann (31) reported that the basal fasting plasma ANF concentration was $0.034 \mathrm{nM}$, and the plasma ANF concentration doubled postprandially. Ogawa et al. (32) reported a similar basal value (0.020-0.027 $\mathrm{nM})$. Lang et al. (24) reported that the basal plasma ANF was $0.018 \mathrm{nM}$, increasing to $0.11 \mathrm{nM}$ after volume expansion. The dose-response data reported in this article (Fig. 2) indicate that changes in ANF concentration in the physiologic range can alter vasopressin-stimulated osmotic water permeability of terminal IMCDs.

Dillingham and Anderson (33) have also reported that ANF inhibits vasopressin-stimulated osmotic water permeability in rabbit cortical collecting ducts, although $2 \mathrm{nM}$ ANF was required for a significant effect; and Samson and Vanetta (34) have reported that ANF inhibits vasotocin-induced water reabsorption in the toad urinary bladder.

Role of cyclic GMP. Cyclic GMP is believed to be the second messenger responsible for many of the actions of ANF (25-29). Previously, Nonoguchi et al. (10) demonstrated that ANF causes a large increase in cyclic GMP accumulation in the rat terminal IMCD. Zeidel et al. (16) have shown that cyclic GMP can mimic the effects of ANF to inhibit ouabaininhibitable sodium-dependent oxygen consumption in rabbit IMCD cell suspensions, and Gunning et al. (35) have shown that these cells possess a high-affinity ANF receptor which is apparently coupled to guanylate cyclase. In the present studies, $0.1 \mathrm{mM}$ cyclic GMP mimicked the effect of ANF to inhibit vasopressin-stimulated osmotic water permeability. These results are therefore compatible with the conclusion that cyclic GMP is the second messenger that mediates the inhibition of osmotic water permeability in response to ANF.

In contrast to the natural form of cyclic GMP, the 8-bromo analogue, 8-bromo-cyclic GMP $(0.1 \mathrm{mM})$ did not affect osmotic water permeability. The 8-bromo modification probably results in much higher intracellular concentrations than with unmodified cyclic GMP. Because of its high concentration, 8-bromo-cyclic GMP may have nonspecific effects on intracellular metabolism that counter the physiological effect of cyclic GMP. For example, 8-bromo-cyclic GMP at high concentrations may mimic cyclic AMP by stimulating protein kinase $A$, thus negating any inhibitory effect it might otherwise have had. Consistent with this possibility, previous studies by Dillingham and Anderson (36) have demonstrated that 0.1 


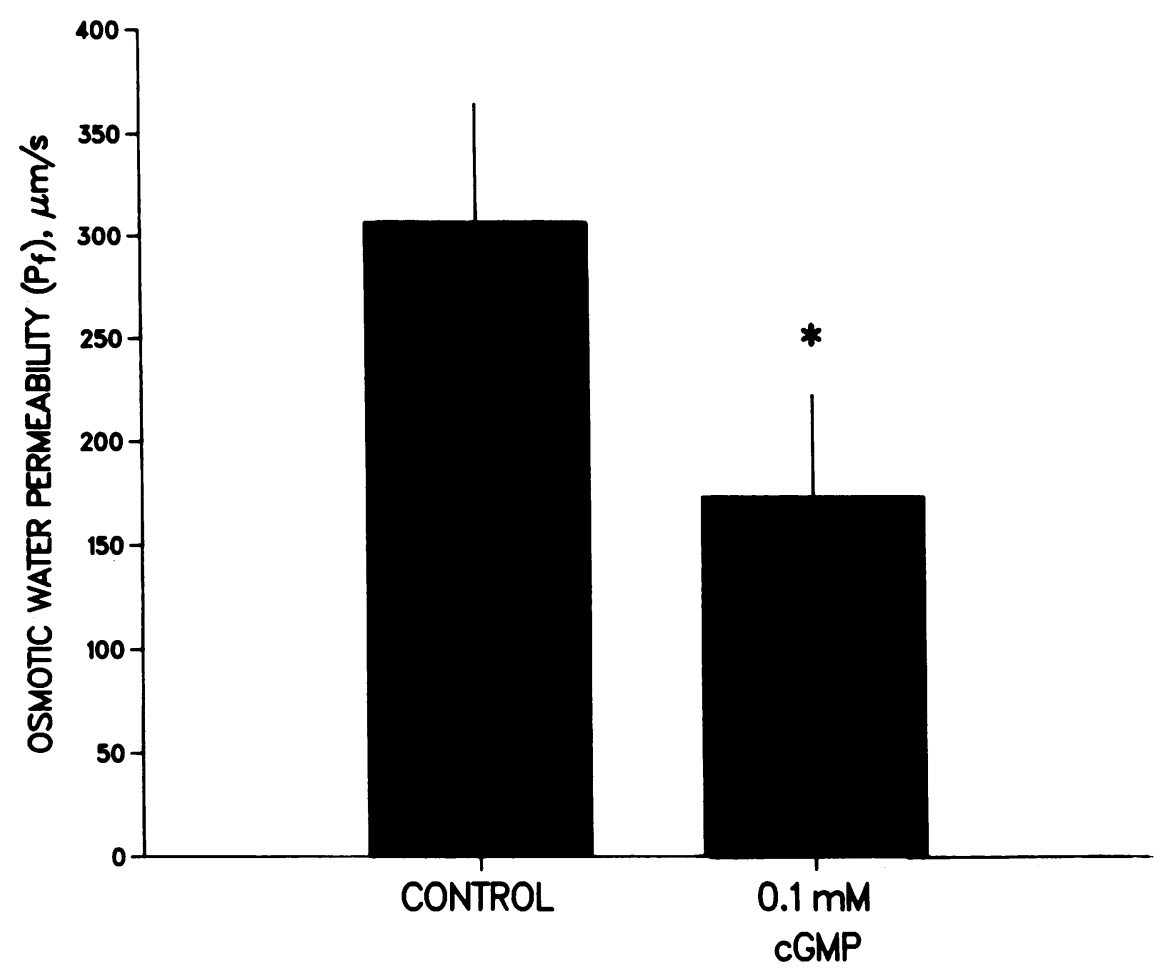

Figure 3. The effect of $0.1 \mathrm{mM}$ cyclic GMP on $P_{\mathrm{f}}$. Vasopressin was present throughout each experiment at a concentration of $10^{-11}$ M. Bars show mean \pm SE for six tubules. ${ }^{*} P$ $<0.002$ by paired $t$ test. Tubule length $550 \pm 60 \mu \mathrm{m}$; tubule inner diameter $32 \pm 2 \mu \mathrm{m}$; collection rate $6.26 \pm 0.86 \mathrm{nl} / \mathrm{min}$ (control), $6.11 \pm 0.64 \mathrm{nl} / \mathrm{min}$ (cyclic GMP).
mM 8-bromo-cyclic GMP increases $P_{\mathrm{f}}$ in the absence of vasopressin in rabbit cortical collecting duct.

Another possibility is that cyclic GMP does not act through protein kinase $G$ but through the activation of cyclic GMPstimulated cyclic AMP phosphodiesterase (37). Cyclic GMP, but not 8-bromo-cyclic GMP, activates the cyclic GMP-stimulated cyclic AMP phosphodiesterase (38), a pattern consistent with that observed in the present study (Figs. 3 and 4). If stimulation of the cyclic AMP phosphodiesterase were the mechanism of control of osmotic water permeability by ANF, then ANF should cause a decrease in the accumulation of cyclic AMP in the absence of IBMX. However, as discussed in the next section, inhibition of cyclic AMP accumulation by ANF was not observed.

Role of cyclic AMP. Dunn et al. (39) have reported that rat plasma vasopressin levels average $0.2 \times 10^{-11} \mathrm{M}$ during water

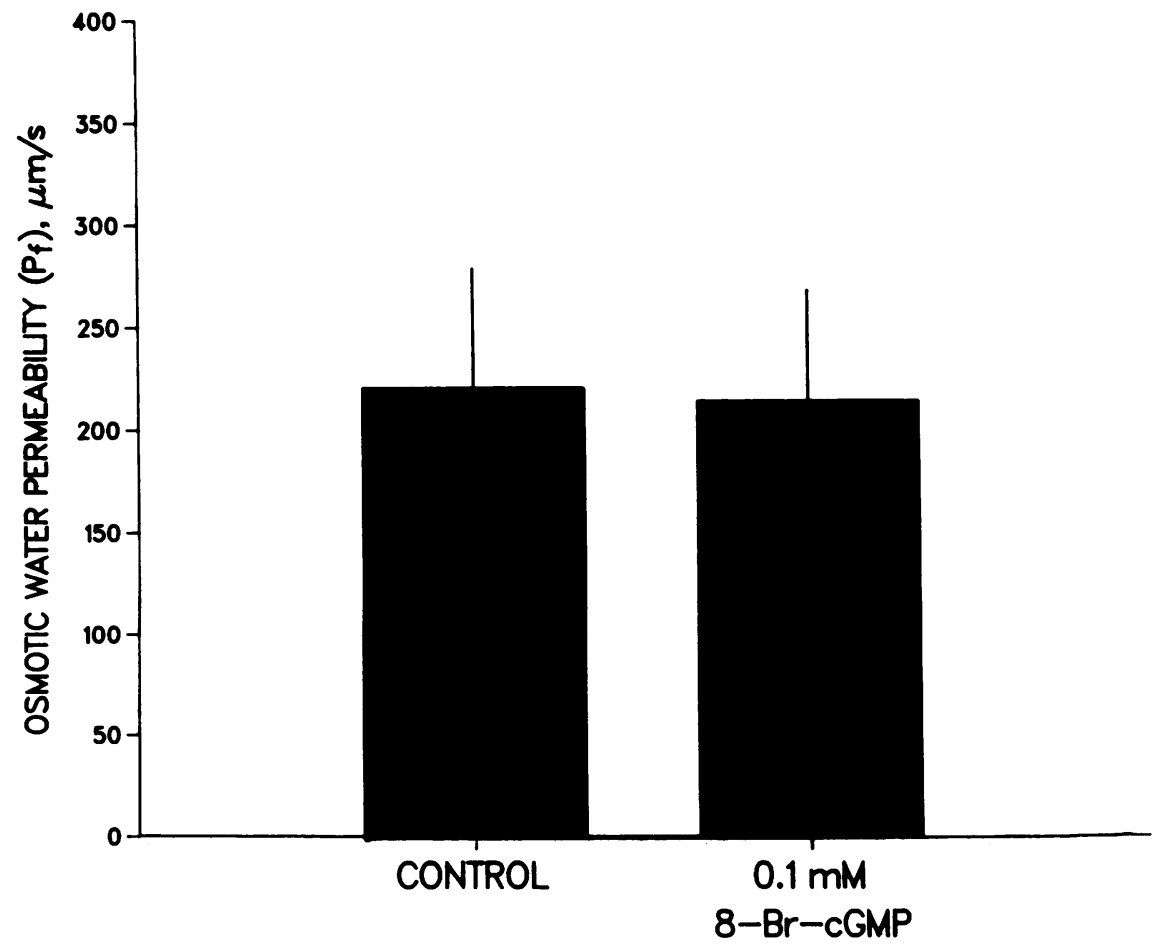

Figure 4. The effect of $0.1 \mathrm{mM} 8$-bromo-cyclic GMP on $P_{\mathrm{f}}$. Vasopressin was present throughout each experiment at a concentration of $10^{-11} \mathrm{M}$. Bars show mean $\pm \mathrm{SE}$ for five tubules. 8-bromo-cyclic GMP had no significant effect on vasopressin-stimulated osmotic water permeability. Tubule length $500 \pm 60 \mu \mathrm{m}$; tubule inner diameter $28 \pm 1 \mu \mathrm{m}$; collection rate $4.91 \pm 0.48 \mathrm{nl} / \mathrm{min}$ (control), $6.12 \pm 0.46 \mathrm{nl} / \mathrm{min}$ (8-bromo-cyclic GMP). 


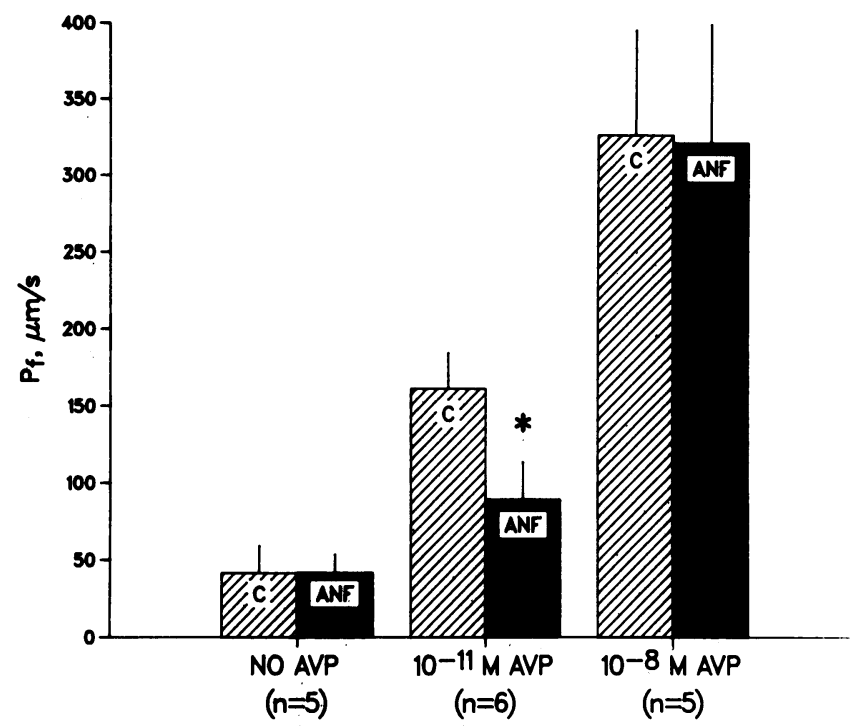

Figure 5. The effect of $100 \mathrm{nM}$ ANF on $P_{\mathrm{f}}$ in the absence of vasopressin (left bars), in the presence of $10^{-11} \mathrm{M}$ vasopressin (center bars), and in the presence of $10^{-8} \mathrm{M}$ vasopressin (right bars). ANF inhibited $P_{\mathrm{f}}$ only in the presence of $10^{-11} \mathrm{M}$ vasopressin. ANF had no significant effect in the absence of vasopressin or in the presence of $10^{-8} \mathrm{M}$ vasopressin. ${ }^{*} P<0.02$ by paired $t$ test.

diuresis and $2.3 \times 10^{-11} \mathrm{M}$ during water deprivation. In the present studies, when the peritubular bath contained a physiologic concentration of vasopressin $\left(10^{-11} \mathrm{M}\right)$, ANF inhibited osmotic water permeability. In contrast, ANF had no effect on osmotic water permeability either in the absence of vasopressin, or in the presence of a supraphysiologic concentration of vasopressin $\left(10^{-8} \mathrm{M}\right)$. It could be argued that the dependence of ANF inhibition of $P_{f}$ on the bath vasopressin concentration could be explained if ANF worked by inhibiting vasopressinstimulated cyclic AMP production. Because much more cyclic

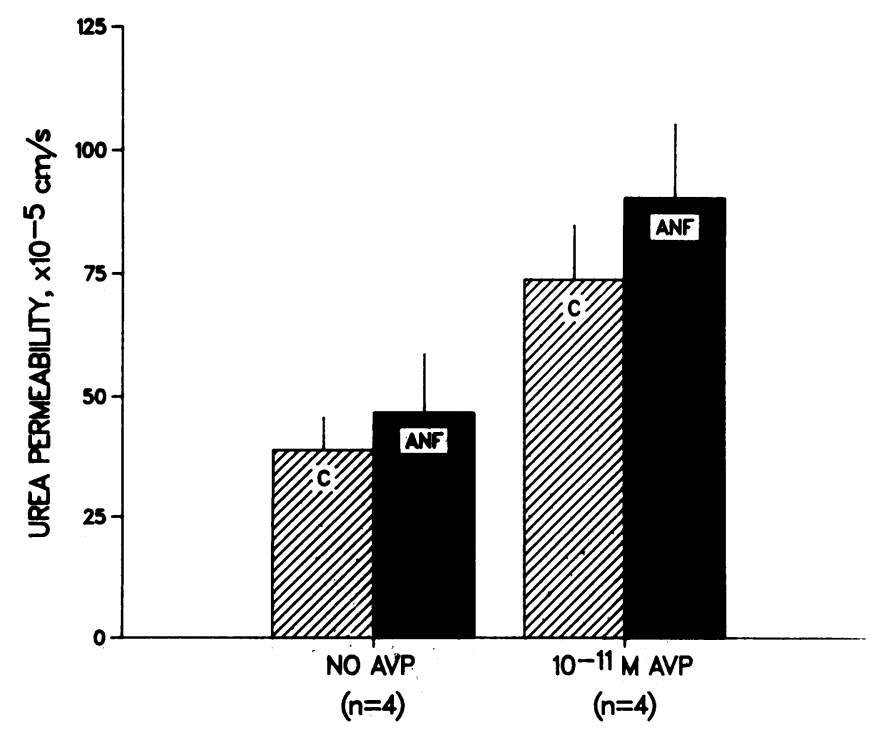

Figure 6. The effect of $100 \mathrm{nM}$ ANF on urea permeability in the absence of vasopressin (left bars) and in the presence of $10^{-11} \mathrm{M}$ vasopressin (right bars). ANF had no effect on urea permeability either in the absence or the presence of vasopressin.
AMP is produced at $10^{-8} \mathrm{M}$ vasopressin than is required for a maximal $P_{\mathrm{f}}$ response (40), inhibition of cyclic AMP accumulation would not necessarily reduce the $P_{\mathrm{f}}$ in the presence of $10^{-8} \mathrm{M}$ vasopressin. Three lines of evidence, however, suggest that ANF does not exert its effect by inhibiting vasopressinstimulated production of cyclic AMP.

First, cyclic AMP accumulation was not affected by ANF in microdissected nonperfused terminal IMCDs. Previously, Nonoguchi et al. (10) showed that ANF did not inhibit cyclic AMP accumulation in IMCDs exposed to $10^{-10} \mathrm{M}$ vasopressin. In the current study, we found no tendency of ANF to inhibit cyclic AMP accumulation in tubules in the presence of $10^{-11} \mathrm{M}$ vasopressin. There was no inhibition regardless of the presence or absence of the phosphodiesterase inhibitor IBMX. The negative result in the absence of IBMX suggests that the effect of ANF on osmotic water permeability is not likely to be due to stimulation of the cyclic AMP phosphodiesterase, as discussed above.

Second, ANF did not inhibit vasopressin-stimulated urea permeability (Fig. 6). Studies by Star et al. (40) have shown that the urea permeability response to vasopressin in rat terminal IMCDs is mediated by cyclic AMP. If the inhibitory effect of ANF on $P_{\mathrm{f}}$ were due to an inhibition of cyclic AMP production, ANF should also inhibit the urea permeability, contrary to our results.

Finally, ANF inhibited 8-bromo-cyclic AMP-stimulated $P_{\mathrm{f}}$. Thus, it appears that the effect of ANF to inhibit vasopressin-stimulated $P_{\mathrm{f}}$ in the rat terminal IMCD is not due to an effect on cyclic AMP production. Rather, the ANF effect is apparently exerted at a site subsequent to cyclic AMP generation in the chain of events that couples vasopressin receptor binding to an increase in osmotic water permeability.

Role of $A N F$ inhibition of $P_{f}$ in the mechanism of $A N F$-induced increases in water and solute excretion. In this article, we have demonstrated a direct effect of ANF to inhibit $P_{\mathrm{f}}$ in the rat terminal IMCD. The effect is large and if present in vivo is predictive of a major effect on renal water excretion. To what extent could the demonstrated effect on water permeability contribute to the observed increases in renal solute excretion in response to ANF?

Many studies have demonstrated that ANF induces a rapid large increase in sodium chloride excretion, followed by a smaller sustained increase (1-3). The sustained increase is almost certainly associated with ANF-induced supression of aldosterone secretion by the adrenals, but this effect may be too slow to account for the rapid transient response. The rapid increase in $\mathrm{NaCl}$ excretion could be in part due to direct effects of $\mathrm{ANF}$ on rat $\mathrm{NaCl}$ transport along the collecting ducts (14-16, 41), or to effects of ANF elsewhere in the kidney (42-44). In addition, there are two ways that inhibition of collecting duct water permeability could contribute to the rapid increase in $\mathrm{NaCl}$ excretion. First, inhibition of collecting duct water absorption by ANF would affect $\mathrm{NaCl}$ concentration gradients across the collecting duct, potentially altering active or passive $\mathrm{NaCl}$ transport. (Inhibition of water absorption would decrease luminal $\mathrm{NaCl}$ concentration, all other factors being equal.) Secondly, by increasing urine flow, ANF could cause reflux of urine into the renal pelvis and fornices allowing $\mathrm{NaCl}$ transfer from the medullary interstitium to the urine via the papillary surface epithelium. Schmidt-Nielsen (45) has shown in rats that under normal conditions pelvic reflux does not occur, but that rising urine flow is associated 


\begin{tabular}{|c|c|c|c|c|c|c|c|c|c|}
\hline \multirow[b]{2}{*}{ Length } & \multirow[b]{2}{*}{ Diameter } & \multirow[b]{2}{*}{ [AVP] } & \multirow[b]{2}{*}{ [ANF] } & \multirow[b]{2}{*}{ Coll. rate } & \multicolumn{3}{|c|}{ Urea concentration } & \multirow[b]{2}{*}{$J_{u}$} & \multirow[b]{2}{*}{$P_{\mathrm{u}}$} \\
\hline & & & & & Perf. & Bath & Coll. & & \\
\hline$\mu m$ & $\mu m$ & $M$ & $M$ & $\mathrm{nl} / \mathrm{min}$ & & & & $\mathrm{pmol} / \mathrm{mm} / \mathrm{min}$ & $\times 10^{-5} \mathrm{~cm} / \mathrm{s}$ \\
\hline \multicolumn{10}{|c|}{ Series $1(n=4)$ : } \\
\hline \multirow[t]{2}{*}{$570 \pm 140$} & $31 \pm 1$ & 0 & 0 & $27.43 \pm 6.37$ & $0.00 \pm 0.00$ & $4.93 \pm 0.00$ & $1.69 \pm 0.12$ & $89.6 \pm 13.7$ & $38.9 \pm 6.6$ \\
\hline & & 0 & $10^{-7}$ & $27.94 \pm 6.47$ & & & $1.90 \pm 0.42$ & $97.8 \pm 19.1$ & $46.7 \pm 11.9$ \\
\hline \multicolumn{10}{|c|}{ Series $2(n=4)$} \\
\hline \multirow[t]{2}{*}{$490 \pm 70$} & $28 \pm 1$ & $10^{-11}$ & 0 & $32.68 \pm 3.04$ & $0.08 \pm 0.01$ & $5.27 \pm 0.12$ & $2.28 \pm 0.12$ & $154.0 \pm 18.8$ & $73.9 \pm 10.9$ \\
\hline & & $10^{-11}$ & $10^{-7}$ & $31.92 \pm 2.50$ & & & $2.66 \pm 0.23$ & $177.4 \pm 22.3$ & $90.5 \pm 14.9$ \\
\hline
\end{tabular}

$P_{\mathrm{u}}$ is not significantly different from control in either series, based on paired $t$ test. All data are presented as mean $\pm \mathrm{SE}$. Diameter is tubule inner diameter. [AVP], vasopressin concentration; [ANF], ANF concentration; $n$, number of tubules; $J_{\mathrm{u}}$, urea flux; $P_{\mathrm{u}}$, urea permeability coefficient; Coll., collection; Perf., perfusate.

with reflux. The high $\mathrm{NaCl}$ permeability of the papillary surface epithelium (46) would permit $\mathrm{NaCl}$ efflux from the medullary interstitium to the pelvic urine when reflux occurs. Thus, ANF-induced pelvic reflux would open a pathway for $\mathrm{NaCl}$ secretion into the urine not present under nondiuretic conditions.

In conclusion, we have shown that ANF inhibits vasopressin-stimulated and cyclic AMP-stimulated $P_{\mathrm{f}}$ in the rat terminal IMCD. This effect is mediated by cyclic GMP and does not appear to be due to an alteration of cyclic AMP metabolism. Rather, the ANF effect is apparently exerted at a site subsequent to cyclic AMP generation in the chain of events that couples vasopressin receptor binding to an increase in $P_{\mathrm{f}}$. ANF-mediated inhibition of collecting duct water permeability may account in part for the observed increases in water and solute excretion in response to ANF.
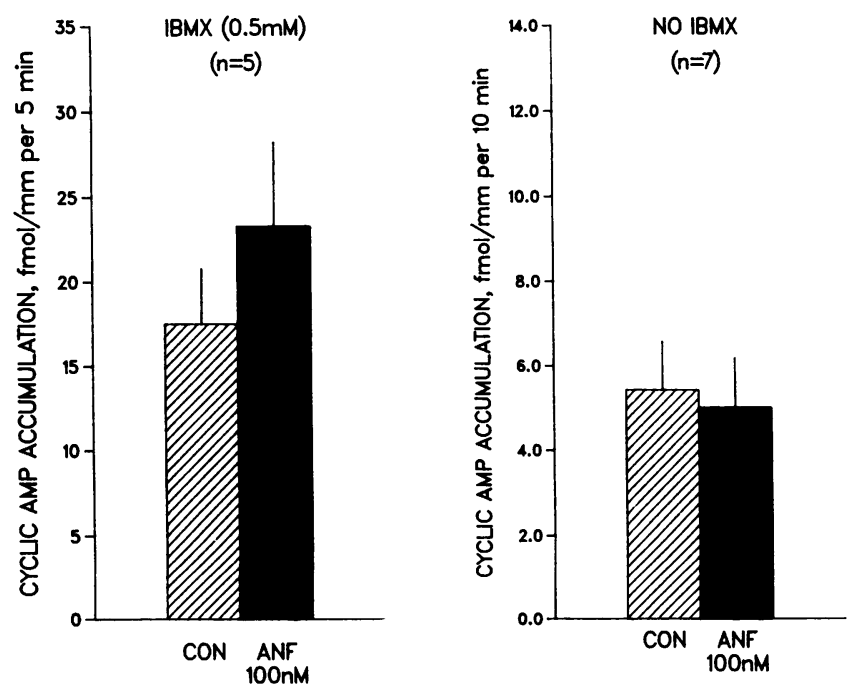

Figure 7. The effect of $100 \mathrm{nM}$ ANF on cyclic AMP accumulation. Vasopressin was present throughout each experiment at a concentration of $10^{-11} \mathrm{M}$. ANF had no significant effect on vasopressin-stimulated cyclic AMP production either in the presence of the phosphodiesterase inhibitor IBMX $(0.5 \mathrm{mM}$, left panel $)$ or in the absence of IBMX (right panel). (Unpaired $t$ tests.)

\section{Acknowledgments}

The authors thank Dr. M. B. Burg and Dr. V. C. Manganiello for their critical reading of this manuscript.

\section{References}

1. Ballermann, B. J., and B. M. Brenner. 1986. Role of atrial peptides in body fluid homeostasis. Circ. Res. 58:619-630.

2. Maack, T., M. J. F. Camargo, H. D. Kleinert, J. H. Laragh, and S. A. Atlas. 1985. Atrial natriuretic factor: structure and functional properties. Kidney Int. 27:607-615.

3. Needleman, P., S. P. Adams, B. R. Cole, M. G. Currie, D. M. Geller, M. L. Michener, C. B. Saper, D. Schwartz, and D. G. Standaert. 1985. Atriopeptins as cardiac hormones. Hypertension. 7:469-482.

4. Briggs, J. P., B. Steipe, G. Schubert, and J. Schnermann. 1982. Micropuncture studies of renal effects of atrial natriuretic substance. Pflügers Arch. Eur. J. Physiol. 395:271-276.

5. Pollack, D. M., and W. J. Arendshorst. 1986. Effect of atrial natriuretic factor on renal hemodynamics in the rat. Am. J. Physiol. 251:F795-F801.

6. Salazar, F. J., M. J. Fiksen-Olsen, T. J. Opgenorth, P. J. Grange1 J. C. Burnett, Jr., and J. C. Romero. 1986. Renal effects of ANF without changes in glomerular filtration rate and blood pressure. Am. J. Physiol. 251:F532-F536.

7. Paul, R. V., K. A. Kirk, and L. G. Navar. 1987. Renal autoregulation and pressure natriuresis during ANF-induced diuresis. Am. J. Physiol. 253:F424-F431.

8. Murray, R. D., S. Itoh, T. Inagami, K. Misono, S. Seto, A. G. Scicli, and O. A. Carretero. 1985. Effects of synthetic atrial natriuretic factor in the isolated perfused rat kidney. Am. J. Physiol. 249:F603F609.

9. Sonnenberg, H., W. A. Cupples, A. J. deBold, and A. T. Veress. 1982. Intrarenal localization of the natriuretic effect of cardiac atrial extract. Can. J. Physiol. Pharmacol. 60:1149-1152.

10. Nonoguchi, H., M. A. Knepper, and V. C. Manganiello. 1987. Effects of atrial natriuretic factor on cyclic guanosine monophosphate and cyclic adenosine monophosphate accumulation in microdissected nephron segments from rats. J. Clin. Invest. 79:500-507.

11. Healy, D. P., and D. D. Fanestil. 1986. Localization of atrial natriuretic peptide binding sites within the rat kidney. Am. J. Physiol. 250:F573-F578.

12. Koseki, C., Y. Hayashi, S. Torikai, M. Furuya, N. Ohnuma, and M. Imai. 1986. Localization of binding sites for $\alpha$-rat atrial natriuretic polypeptide in rat kidney. Am. J. Physiol. 250:F210-F216.

13. Chai, S. Y., P. M. Sexton, A. M. Allen, R. Figdor, and F. A. O. 
Mendelsohn. 1986. In vitro autoradiographic localization of ANP receptors in rat kidney and adrenal gland. Am. J. Physiol. 250:F753F757.

14. Sonnenberg, H., U. Honrath, C. K. Chong, and D. R. Wilson. 1986. Atrial natriuretic factor inhibits sodium transport in medullary collecting duct. Am. J. Physiol. 250:F963-F966.

15. Van de Stolpe, A. and R. L. Jamison. 1988. Micropuncture study of the effect of ANP on the papillary collecting duct in the rat. Am. J. Physiol. 254:F477-F483.

16. Zeidel, M. L., J. L. Seifter, S. Lear, B. M. Brenner, and P. Silva. 1986. Atrial peptides inhibit oxygen consumption in kidney medullary collecting duct cells. Am. J. Physiol. 251:F379-F383.

17. Sands, J. M., H. Nonoguchi, and M. A. Knepper. 1987. Vasopressin effects on urea and $\mathrm{H}_{2} \mathrm{O}$ transport in inner medullary collecting ducts. Am. J. Physiol. 253:F823-F832.

18. Morgan, T., and R. W. Berliner. 1968. Permeability of the loop of Henle, vasa recta, and collecting duct to water, urea, and sodium. Am. J. Physiol. 215:108-115.

19. Rocha, A. S., and L. H. Kudo. 1982. Water, urea, sodium, chloride, and potassium transport in the in vitro isolated perfused papillary collecting duct. Kidney Int. 22:485-491.

20. Sands, J. M., and M. A. Knepper. 1987. Urea permeability of mammalian inner medullary collecting duct system and papillary surface epithelium. J. Clin. Invest. 79:138-147.

21. Burg, M. B. 1972. Perfusion of isolated renal tubules. Yale J. Biol. Med. 45:321-326.

22. Al-Zahid, G., J. A. Schafer, S. L. Troutman, and T. E. Andreoli. 1977. The effect of antidiuretic hormone on water and solute permeation, and the activation energies for these processes, in mammalian cortical collecting tubules: evidence for parallel ADH-sensitive pathways for water and solute diffusion in luminal plasma membranes. $J$. Membr. Biol. 31:103-130.

23. Knepper, M. A., D. W. Good, and M. B. Burg. 1985. Ammonia and bicarbonate transport by rat cortical collecting ducts perfused in vitro. Am. J. Physiol. 249:F870-F877.

24. Lang, R. E., H. Tholken, D. Ganten, F. C. Luft, H. Ruskoaho, and $\mathrm{Th}$. Unger. 1985. Atrial natriuretic factor-a circulating hormone stimulated by volume loading. Nature (Lond.). 314:264-266.

25. Winquist, R. J., E. P. Faison, S. A. Waldman, K. Schwartz, F. Murad, and R. M. Rapoport. 1984. Atrial natriuretic factor elicits an endothelium-independent relaxation and activates particulate guanylate cyclase in vascular smooth muscle. Proc. Natl. Acad. Sci. USA. 81:7661-7664.

26. Tremblay, J., R. Gerzer, S. C. Pang, M. Cantin, J. Genest, and P. Hamet. 1985. ANF stimulation of detergent-dispersed particulate guanylate cyclase from bovine adrenal cortex. FEBS (Fed. Eur. Biochem. Soc.) Lett. 194:210-214.

27. Tremblay, J., R. Gerzer, P. Vinay, S. C. Pang, R. Beliveau, and P. Hamet. 1985. The increase of cyclic GMP by atrial natriuretic factor correlates with the distribution of particulate guanylate cyclase. $F E B S$ (Fed. Eur. Biochem. Soc.) Lett. 181:17-22.

28. Murad, F. 1986. Cyclic guanosine monophosphate as a mediator of vasodilation. J. Clin. Invest. 78:1-5.

29. Leitman, D. C., J. W. Andresen, T. Kuno, Y. Kamisaki, J-K. Chang, and F. Murad. 1986. Identification of multiple binding sites for atrial natriuretic factor by affinity cross-linking in cultured endothelial cells. J. Biol. Chem. 261:11650-11655.

30. DeBold, A. J., H. B. Borenstein, A. T. Veress, and H. Sonnenberg. 1981. A rapid and potent natriuretic response to intravenous injection of atrial myocardial extract in rats. Life Sci. 28:89-94.

31. Ballermann, B. J. 1988. A highly sensitive radioreceptor assay for atrial natriuretic peptide (ANP) in rat plasma. Am. J. Physiol. 254:F159-F163.

32. Ogawa, K., M. A. Henry, J. Tange, E. A. Woodcock, and C. I. Johnston. 1987. Atrial natriuretic peptide in dehydrated Long-Evans rats and Brattleboro rats. Kidney Int. 31:760-765.

33. Dillingham, M. A. and R. J. Anderson. 1986. Inhibition of vasopressin action by atrial natriuretic factor. Science (Wash. DC). 231:1572-1573.

34. Samson, W. K., and J. C. Vanetta. 1986. Atrial natriuretic factor inhibits vasotocin-induced water reabsorption in the toad urinary bladder. Proc. Soc. Exp. Biol. Med. 181:169-172.

35. Gunning, M., B. J. Ballermann, B. M. Brenner, P. Silva, and M. L. Zeidel. 1988. Characterization of ANP receptors in rabbit inner medullary collecting duct cells. Am. J. Physiol. 255:F324-F330.

36. Dillingham, M. A., and R. J. Anderson. 1987. Evidence for a functional guanylate cyclase/cyclic GMP system which increases hydraulic conductivity in rabbit cortical collecting tubule. Kidney Int. 31:445. (Abstr.)

37. Hartzell, H. C., and R. Fischmeister. 1986. Opposite effects of cyclic GMP and cyclic AMP on $\mathrm{Ca}^{2+}$ current in single heart cells. Nature (Lond.). 323:273-275.

38. Moss, J., V. C. Manganiello, and M. Vaughan. 1977. Substrate and effector specificity of a guanosine $3^{\prime}: 5^{\prime}$-monophosphate phosphodiesterase from rat liver. J. Biol. Chem. 252:5211-5215.

39. Dunn, F. L., T. J. Brennan, A. E. Nelson, and G. L. Robertson. 1973. The role of blood osmolality and volume in regulating vasopressin secretion in the rat. J. Clin. Invest. 52:3212-3219.

40. Star, R. A., H. Nonoguchi, R. B. Balaban, and M. A. Knepper. 1988. Calcium and cyclic AMP as second messengers for vasopressin in the rat inner medullary collecting duct. J. Clin. Invest. 81:18791888.

41. Nonoguchi, H., J. M. Sands, and M. A. Knepper. 1988. Atrial natriuretic factor inhibits reabsorption of sodium and fluid in isolated perfused cortical collecting ducts from rats. Clin. Res. 36:524A. (Abstr.)

42. Huang, C.-L., and M. G. Cogan. 1987. Atrial natriuretic factor inhibits maximal tubuloglomerular feedback response. Am. J. Physiol. 252:F825-F828.

43. Camargo, M. J. F., H. D. Kleinert, S. A. Atlas, J. E. Sealey, J. H. Laragh, and T. Maack. 1984. Ca-dependent hemodynamic and natriuretic effects of atrial extract in isolated rat kidney. Am. J. Physiol. 246:F447-F456.

44. Cogan, M. G. 1986. Atrial natriuretic factor can increase renal solute excretion primarily by raising glomerular filtration. Am. J. Physiol. 250:F710-F714.

45. Schmidt-Nielsen, B. 1987. The renal pelvis. Kidney Int. 31:621-628.

46. Packer, R. K., J. M. Sands, and M. A. Knepper. 1988. Sodium chloride and osmotic water permeabilities of isolated rabbit papillary surface epithelium: effects of vasopressin. Kidney Int. 33:280. (Abstr.) 